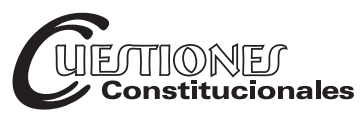

Revista Mexicana de Derecho Constitucional

Núm. 41, julio-diciembre 2019

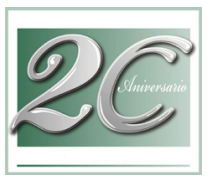

\title{
El sistema presidencial argentino como un sistema resiliente*
}

\author{
The Argentine Presidential System as a Resilient System
}

\author{
Juan M. MOCOROA**
}

\begin{abstract}
RESUMEN: La reforma constitucional argentina intentó atenuar al sistema presidencial. A casi veinticinco años de aquella modificación, es dable interrogarse si ese objetivo fue alcanzado. Es decir, si fue cumplida en el marco de nuestra práctica constitucional. Los diagnósticos efectuados son, en general, negativos. En este trabajo intentaré demostrar que el presidencialismo argentino es un paradójico caso de sistema resiliente. Ante cualquier intento de atenuación resulta dotado de mayores credenciales de legitimidad o mayores competencias formales en el texto constitucional, o bien los intentos resultan únicamente vacuos. A partir de eso, se intenta reconstruir conceptualmente esta situación.
\end{abstract}

Palabras clave: Presidencialismo, sistema político, estabilidad, democracia, resiliencia.
ABSTRACT: The Argentine constitutional reform tried to attenuate the presidential system. Almost twenty-five years after that modification, it is possible to question whether that objective was reached. That is, if it was fulfilled within the framework of our constitutional practice. The diagnoses made are, in general, negative. In this paper I will try to show that Argentine presidentialism is a paradoxical case of a resilient system. In the face of any attempt at mitigation, it is endowed with greater legitimacy credentials or greater formal competencies in the constitutional text; or the attempts are only vacuous. From that, we try to reconstruct this situation conceptually.

Keywords: Presidentialism, political system, stability, democracy, resilience.

* Este trabajo se enmarca en el proyecto de investigación Tipo I "La Constitución Nacional ante el Tribunal Superior de Justicia de Córdoba: control de constitucionalidad e interpretación constitucional”, financiado por la Universidad Siglo 21. Deseo agradecer los comentarios, observaciones y críticas efectuadas por los evaluadores anónimos provistos por la Revista, que sirvieron para mejorar sustancialmente este texto. Las oscuridades y errores que se han mantenido son, sin embargo, de mi entera responsabilidad.

** Abogado por la Universidad Nacional de Córdoba, Argentina (UNC); Master en Global Rule of Law and Constitutional Democracy (Universidad de Génova); docente de Derecho Constitucional (UNC); jmmocoroa@gmail.com. 
SUMARIO: I. Introducción. II. Resiliencia institucional: el presidencialismo como sistema institucional "resiliente". III. Presidencialismo, resiliencia y decretos de necesidad y urgencia: una pequeña muestra de la práctica constitucional argentina. IV. Presidencialismo y resiliencia institucional. V. Conclusión.

VI. Bibliografia.

\section{INTRODUCCIÓN}

Una de las ideas fuerza de la reforma constitucional argentina de 1994 fue atenuar al sistema presidencial. ${ }^{1}$ Esta finalidad estaba motivada en un hecho notorio: el titular del Poder Ejecutivo ejercía sus competencias con escasos controles efectivos. En efecto, la propia Corte Suprema de Justicia de la Nación tuvo oportunidad de analizar esta causa eficiente del proceso constituyente argentino:

...la reforma constitucional enunció entre sus objetivos "atenuar el presidencialismo", al mismo tiempo que consignó la necesidad de "modernizar y fortalecer el Congreso" y "fortalecer los mecanismos de control", todo ello directamente relacionado con el fin de "perfeccionar el equilibrio de poderes". La metodología a la que se acudió fue la de incorporar ciertas facultades excepcionales de los poderes constituidos, con el fundamento de que aquello significaba la institucionalización de los mecanismos de control a los que se los sometía. ${ }^{2}$

A casi veinticinco años de aquella modificación, es dable interrogarse si ese objetivo fue alcanzado. Es decir, si es posible constatar que aquella primigenia idea - i. e., atenuación del presidencialismo - pudo, efectivamente, ponerse en práctica. Para eso resulta fundamental analizar la interacción y dinámica generada por la propia Constitución en el proceso post-constituyente. Los diagnósticos efectuados son, en general, negativos. ${ }^{3}$ En líneas generales, la

1 Sobre las "ideas-fuerza" de la reforma constitucional, véase Hernández, Antonio M. (h), Federalismo, autonomía municipal y ciudad de Buenos Aires en la reforma constitucional de 1994, Buenos Aires, Depalma, 1997, passim.

2 CSJN, Fallos, 333:633 (“Consumidores Argentinos c/ EN - PEN - Dto. 558/02 Ley 20.091 s/ Amparo Ley 16.986” [19/5/2010]).

3 La literatura argentina, en líneas generales, resulta sumamente crítica tanto de la 
doctrina constitucional argentina le reprocha al constituyente de 1994 que no sólo no lo limitó, sino que, al contrario, lo dotó de mayores competencias. ${ }^{4}$

Entiendo que, sin embargo, esto es un error de interpretación. No obstante, para sostener por qué considero que esto es así, es necesario que aclare una cuestión más general. A mi modo de ver, y eso es lo que intentaré demostrar en este trabajo, el presidencialismo argentino qua sistema institucional coloca a quienes están en posibilidad de realizar una reforma constitucional que modifique las competencias del Poder Ejecutivo ante un dilema de hierro, aun cuando no sean conscientes. El hiperpresidencialismo argentino, o bien fagocita todo intento atenuador -i.e., resulta inútil, vacuo-, o bien resulta dotado de mayores credenciales de legitimidad o mayores competencias formales en el texto constitucional -i.e., resulta contrario a lo esperado/buscado- Si este dilema fuera cierto, lo que así argumentaré, podemos proceder como con todo razonamiento dilemático. Por un lado, negar la verdad o corrección de alguno o de ambos cuernos

propia regulación constitucional de las instituciones excepcionales que fueron incorporadas con el objetivo de limitar, antes que de dotar de mayores competencias, al Poder Ejecutivo Nacional, como también respecto de la regulación efectuada en el periodo post-constituyente. Véase, entre muchos otros autores, Alegre, Marcelo, "Democracia sin presidentes”, en Gargarella, Roberto (coord.), Teoría y crítica del derecho constitucional, Buenos Aires, Abeledo-Perrot, 2008, pp. 43 y ss., y Arrimada, Lucas, "Derecho, moral y política. Derecho constitucional, moral institucional y política democrática: sobre frenos, puentes y motores en la democracia deliberativa", en Gargarella, Roberto (coord.), op. cit., pp. 87 y ss.; Hernández, Antonio M. (h), "El Poder Ejecutivo”, en id. (dir.), Derecho constitucional, Buenos Aires, La Ley, 2012, t. II, pp. 1296 y ss.; Hernández, Antonio María (h), "Presidencialismo y federalismo en la Argentina", en Sabsay, Daniel (dir.), Manili, Pablo L. (coord.), Constitución de la Nación Argentina y normas complementarias. Análisis doctrinario y jurisprudencial, Buenos Aires, Hammurabi, 2010, t. IV, pp. 37 y ss.; Hernández, Antonio María (h), Las emergencias y el orden constitucional, 2 a. ed., México, UNAM-Rubinzal-Culzoni, 2003, passim; Riberi, Pablo C., "El presidencialismo exánime. Por más cooperación y mejores controles en nuestro sistema político", en varios autores, Constitución de la Nación Argentina. Con motivo del sesquicentenario de su sanción, Santa Fe, Asociación Argentina de Derecho Constitucional, 2003, t. II, pp. 291 y ss.

4 A partir de lo que se dice en el cuerpo del texto, debería quedar claro que, al menos para la literatura constitucional y politológica argentina, el problema de la dinámica entre el Congreso de la Nación y el Poder Ejecutivo no se refiere tanto a la "falta de sanción de leyes que satisfagan la demanda social", sino que, antes bien, está dirigida derechamente a criticar y resaltar la falta de controles expresos, eficientes y eficaces por el Poder Legislativo al ejercicio de potestades legisferantes del Ejecutivo. Véase, sobre esto, Mocoroa, Juan M., "Atribuciones del Poder Ejecutivo Nacional”, en Hernández, Antonio M. (h) (dir.), Derecho constitucional, op. cit., pp. 1351 y ss. (en especial pp. 1336/1389). 
del dilema. Por otro, podemos intentar disolverlo. Ahora, como creo que esas premisas son correctas, la única forma de afrontarlo es proceder a su disolución. Empero, para hacerlo, debería pensarse en mutar de sistema institucional. Es que, en verdad, la dinámica de los actores institucionales en Argentina resulta inescapable. Sin embargo, no estoy seguro de que esa sea una solución positiva y, mucho menos, de mis posibilidades de justificación en este trabajo.

Más modestamente, aquí sólo intentaré reconstruir conceptualmente esta situación. Para ello introduciré un concepto que pretenderé explicativo de este marco problemático. A tales efectos, me referiré a la posible existencia de una propiedad disposicional en el sistema institucional argentino. Ante la falta de un concepto más apropiado, usaré la noción de "resiliencia". Con esto, tengo una finalidad explicativa y reconstructiva de conocimiento. Por eso, y para alcanzar ese objetivo, en este trabajo se utilizarán las herramientas del análisis conceptual para ofrecer una reconstrucción racional de los conceptos relevantes. En particular en lo que se refiere al concepto de propiedad disposicional, estabilidad y resiliencia. Asimismo, se efectuará un análisis de corte dogmático para identificar, interpretar y sistematizar las cláusulas constitucionales pertinentes y relevantes de la Constitución de la Nación Argentina. Todas estas herramientas serán utilizadas también para verificar la utilidad del concepto propuesto y cómo se ha desarrollado la práctica constitucional argentina en el ámbito de la jurisprudencia de la Corte Suprema de Justicia de la Nación.

\section{RESILIENCIA INSTITUCIONAL: EL PRESIDENCIALISMO COMO SISTEMA INSTITUCIONAL "RESILIENTE"}

Antes de plantear y reconstruir este punto, es mi interés la introducción de un concepto que, pienso, podrá dar cuenta de la situación a la que me acabo de referir en la introducción -i.e., la dificultad que debe afrontar el constituyente argentino al momento de modificar las competencias del Poder Ejecutivo Nacional- Algunos modernos desarrollos de la psicología se ocupan del análisis de un concepto que, creo, puede ser de utilidad. De lo que se ocupan estos análisis teóricos es de investigar lo que consideran una propiedad "innata". En términos generales, se reconoce que algunos individuos poseen la capacidad de sobreponerse a situaciones de dolor e incomodidad. Las situaciones traumáticas, parecería, no pueden hacer 
mella en su constitución; quizá, incluso, lo que hacen es moldear su propia personalidad: fortalecerlas.

En el ámbito de la ciencia política se ha empleado este término para referirse a cuestiones vinculadas con el sistema institucional. En efecto, Pérez Liñán y Mainwaring utilizan el término resilient vinculado a situaciones de quiebre y supervivencia de la democracia. Para ellos, el presidencialismo podría ser más resiliente en caso de una más fuerte preferencia normativa por la democracia entre las fuerzas políticas que participan competitivamente en las democracias de América Latina. Las variables con las que cuentan en su análisis son (i) el carácter de las políticas - i. e., radicales vs. moderadas - y (ii) la preferencia normativa por la democracia. ${ }^{5}$ De otro costado, se ha sostenido que

...el sistema político tolera cierto tipos de conflictos salvables entre órganos del Estado. Otros, en cambio, son insalvables. Son los conflictos que el sistema necesita vitalmente eliminar para poder funcionar. $\mathrm{O}$ el conflicto desaparece o el Estado se paraliza. Ergo, el conflicto debe desaparecer y el modo de que desaparezca, por lo común, consiste en la derrota de la parte más débil. ${ }^{6}$

Si intentásemos trasladar estas consideraciones al ámbito institucional, no sería erróneo considerar que el presidencialismo hipertrofiado argentino es un sistema resiliente. Ahora bien, esta situación no es posible subsumirla bajo el prisma conceptual al que acabo de aludir. Por el contrario, pienso, es posible simplificar el análisis brindando dos categorías que se derivarían de aquel concepto: por un lado, una variante negativa y, por otro, una positiva. ${ }^{7}$

5 Cfr. Mainwaring, Scott y Pérez Liñán, Aníbal, "Democratic breakdown and survival", Journal of Democracy, volume 24, number 2, April 2013, pp. 123-137. Sin embargo, por lo que diré en el texto, me parece que estos autores se refieren a una idea distinta y que, quizá, podría — según el caso — subsumirse bajo la noción de estabilidad/gobernabilidad según las expliqué anteriormente.

6 Oyhanarte, Julio, "Historia del Poder Judicial", en id., Recopilación de sus obras, Buenos Aires, La Ley, pp. 139-211, p. 176.

7 A partir de una observación muy inteligente de uno de los dictaminadores anónimos seleccionados por la dirección editorial de esta Revista, aclaro que no se trata de un uso valorativo de esos términos. Esto es, la propuesta de análisis conceptual que efectúo no tiene una carga emotiva especial en la que pudieran señalarse los términos "positivo" y "negativo" con expectativas favorables o desfavorables de parte de los usuarios del sistema institucional. Por el contrario, sólo intento remarcar cómo en un caso puede fa- 
Por resiliencia en sentido negativo (i.e., $\mathrm{R}-$ ), entiendo la característica que posee el sistema institucional argentino de resistir todos, y cada uno, de los intentos de atenuación que se han formulado a lo largo de su historia constitucional. Con ello quiero hacer asequible, conceptualmente, el hecho de que los inputs atenuadores que, históricamente, se han presentado en Argentina han sido vanos. Esto es, no han sido eficaces para lograr el objetivo al que estaban destinados. La explicación de este fracaso, pienso, puede tener dos alternativas: (i) los propios medios institucionales seleccionados para el logro de esa finalidad no son adecuados, y (ii) es el propio sistema institucional el que genera las "condiciones de resiliencia negativa". En tal sentido, es el presidencialismo que, por su dinámica, tiene la predisposición, tendencia o propensión a transformar esos "parches" institucionales en inidóneos, figuras decorativas con las que, de algún modo, calmar conciencias institucionales.

No obstante, no es este el único problema. En efecto, derivada de la misma idea de perdurabilidad de sus características principales, es posible indicar la existencia de, además, otra propiedad aún más preocupante. Me refiero a la que indiqué como "resiliencia positiva" (i.e., $\mathrm{R}+$ ). Según ésta, podemos describir la siguiente situación: pese a los intentos de apaciguamiento de las elefantiásicas competencias del Poder Ejecutivo, no sólo que ellos se tornan vanos (supuesto característico de la $\mathrm{R}-$ ), sino que, contrariamente a lo pronosticado, el sistema presidencial se torna más vigoroso. Con esta idea, entonces, sugiero que cualquier intento de atenuación tiene un pronóstico asegurado. Esto es, tiende a fortalecer al presidencialismo. Este último sería un caso claro de lo denominado por Jean Paul Sartre como "contrafinalidad", según la cual las consecuencias no intencionales de una cierta acción colectiva hacen que todo el mundo esté peor, contrariando la intención buscada. ${ }^{8} \mathrm{El}$ sistema que padecemos convierte en beneficio propio,

vorecer o compeler al otorgamiento de competencias - i. e., positivo- o a funcionar con un carácter más reactivo - i. e., negativo - a fin de rechazar las pretensiones de los constituyentes con pretensiones de modificación de las competencias del Poder Ejecutivo.

8 Cfr. Elster, Jon, Tuercas y tornillos. Una introducción a los conceptos básicos de las ciencias sociales, trad. de Antonio Bonanno, Barcelona, Gedisa, 1990, p. 99. Como ejemplos de ello, este autor cita los siguientes: cuando todos se ponen de pie para tener una mejor visión del juego, nadie lo logra y todos se cansan de estar de pie; cuando todos tratan de sacar simultáneamente dinero del banco, todos pueden perder sus depósitos; cuando todas las firmas tratan de sobrevivir a una recesión reduciendo los salarios, la consiguiente pérdida de poder adquisitivo puede convertir la recesión en una completa depresión. 
incluso, esos intentos de restricción. No pueden insertarse cambios institucionales acordes con la finalidad planteada. Por el contrario, al responder de tal forma, lo que sucede es que, contrariando los inputs iniciales, el sistema las convierte en su provecho. Así, pese a la pretendida atenuación del presidencialismo por parte de la Reforma Constitucional de 1994, lo que ha sucedido es inversamente proporcional al diseño esperado. El sistema presidencialista argentino no sólo que no se habría atenuado, sino que, a la inversa, ha generado las condiciones necesarias para reforzar las propias competencias del titular del Poder Ejecutivo Nacional.

Es necesario detenerse un poco más en los pares de conceptos expuestos. A mi criterio, ambos términos podrían ser reconstruidos en términos de "propiedad disposicional". Ernesto Garzón Valdes, al analizar el concepto de "estabilidad", nos dice que éste tiene una particularidad que lo hace sumamente complejo. La propiedad "estable" no es ni normativa ni descriptiva, en tanto propiedad. Sin embargo, el juicio que efectuamos sobre la estabilidad de un sistema político es de tipo descriptivo. De todos modos, aun aceptando esto, las dificultades no desaparecen. En efecto, aun cuando se acepte su naturaleza descriptiva, es menester determinar cuáles son los datos de corte empírico de los que depende su verdad o falsedad. ${ }^{9}$ Es que la propiedad de la que se trata - i. e., estabilidad - no es observable en forma directa a través de los sentidos. Para poder afrontar y superar esta dificultad, desarrolla — como adelanté - el sentido de las "propiedades disposicionales". Así, este autor enseña que "...los enunciados que predican propiedades disposicionales indican que la persona o cosa de que se trata tiene una cierta capacidad, tendencia o propensión. No son informes sobre estados de cosas observados ni narran incidentes, pero están íntimamente vinculados con éstos pues solo son verdaderos si los satisfacen". ${ }^{10}$

Pienso que para comprender, acabadamente, la característica a la que me refiero, sería útil entenderla como una propiedad disposicional. De este modo, pienso que sería conceptualmente adecuado extender aquellas consideraciones al término propuesto. En este sentido, entonces, lo que denota el

9 Cfr. Garzón Valdés, Ernesto, "El concepto de estabilidad en los sistemas políticos", en Garzón Valdés, Ernesto, Derecho, ética y política, Madrid, Centro de Estudios Constitucionales, 1993, p. 577.

10 El ejemplo clásico utilizado para la comprensión de este tipo de propiedades es la solubilidad del azúcar. Ésta requiere la existencia de ciertas condiciones que, presentes ellas, determinarán la verdad o falsedad, en su caso, de la proposición "el azúcar es soluble". Véase Garzón Valdés, Ernesto, op. cit., p. 577. 
concepto de resiliencia es que un sistema presidencial, dadas sus especiales características, tiene cierta capacidad, propensión o tendencia, y la tiene para responder de un modo muy preciso a los intentos de atenuación que, externamente, se prediquen. Entonces, deberíamos situarnos en aquellos supuestos en los que existan intenciones de modificar las competencias del titular del Poder Ejecutivo para aminorarlas. A esta situación podríamos denominarla "circunstancias de atenuación". En estas situaciones, y más allá de las modificaciones constitucionales formales que se efectúen sobre el texto constitucional, el sistema institucional genera una dinámica institucional muy particular. Es así que para que estemos en condiciones de afirmar que un sistema institucional presidencialista es resiliente, recibirá las pretensiones de parte de quienes estén en la posibilidad de ejercer influencia sobre su construcción, transformándolas. Para que estas circunstancias estén presentes es menester que se den las siguientes condiciones: (i) el sistema institucional tienda a asegurar la "eficacia de la decisión", antes que el control o la deliberación y el debate en su adopción; (ii) esta opción importe una restricción severa a la efectividad de instancias de control producidas constitucionalmente, $y$, por último, (iii) que el contexto en el que se produzca esta situación provoque intentos de atenuación que, desde un punto de vista formal -i. e. modificación de la Constitución-, hayan sido efectivas. Sin duda, (i) y (ii) establecen las causas que habrán de motivar la actuación en (iii); es más, quizá justamente sean aquellas las que motivan a la generación de este contexto de reforma.

De cualquier forma, no es importante para el argumento que me detenga en el análisis de aquellas causas. Sin embargo, sí lo son las razones que puedan motivar que una reforma atenuadora sea, en rigor, intentar dotar al sistema de salidas institucionales para situaciones de bloqueo entre Legislativo y Ejecutivo. Aquí resulta relevante recordar que, me parece, puede encontrarse en un movimiento pendular de la historia política de los países de América Latina. Recuérdese que la justificación del presidencialismo prometía, al menos, dos baluartes: (i) eficacia y (ii) estabilidad. ${ }^{11}$ Ahora bien, esa experiencia, por el contrario, demostró una tendencia pendular hacia los extremos opuestos de esos objetivos. Esta oscilación, sin duda, desarrolló un desplazamiento desde la impotencia hacia la inestabili-

11 Cfr., entre muchos otros, Mocoroa, Juan M., “Alberdi, las «Bases» y la construcción del Poder Ejecutivo Nacional”, Revista Mexicana de Historia del Derecho, México, segunda época, vol. XXVI, julio-diciembre de 2012, pp. 147-198. 
dad, ${ }^{12}$ y, con ello, hacia el absolutismo y despotismo. En efecto, según Bouzat, la dinámica pendular del presidencialismo puede ser identificada con una paradoja. En las presidencias fuertes, los elementos consensuales del sistema no ejercen un control efectivo sobre el presidente, mientras que en los débiles, obstaculizan la gestión. ${ }^{13}$ De ahí que, entonces, académicamente resurgió la necesidad de interrogarse por los incentivos que genera este sistema institucional. El interrogante es, básicamente, identificar la relación del sistema con estos resultados desfavorables y desastrosos. ${ }^{14}$

Como dije, la posibilidad de que el output institucional consista en que los intentos de atenuación o sean vanos o doten de mayores competencias al presidencialismo, depende de ciertas circunstancias. A éstas, como ya adelanté, las llamo "circunstancias de atenuación". Mi idea es que, dadas estas circunstancias, el presidencialismo hipertrofiado argentino tenderá, propenderá o tendrá la capacidad de, por un lado, resultar ileso (i. e., lo que llamé resiliencia en sentido negativo, "R-"), o bien, dotado de, ya sea mayores credenciales de legitimidad democrática (por ejemplo, es el caso de la intervención del Congreso en el dictado de los Decretos de Necesidad y Urgencia), o, directamente, de mayores competencias, pues, desde un punto de vista formal, carecía de ellas con anterioridad a la intervención del constituyente (i. e., lo que llamé resiliencia en sentido positivo, "R+"). El ejemplo claro, en este sentido, es la incorporación del artículo 99, inciso 3, a la Constitución de la Nación Argentina, que prevé la posibilidad de que, en determinadas circunstancias, el Poder Ejecutivo esté facultado para dictar medidas de contenido legislativo de manera autónoma.

12 Caracteriza la dinámica histórico-política del presidencialismo argentino en similares términos, Acuña, Carlos, "Contribución”, en Ferraro, Ricardo y Rapapport, Luis, Presidencialismo absoluto y otras verdades incómodas, Buenos Aires, El Ateneo, 2008 , pp. 26 y 27. Un certero análisis respecto a la interrelación del presidencialismo argentino entre la ineficacia, inestabilidad y falta de control, en Riberi, Pablo C., op . cit., passim.

13 Cfr. Bouzat, Roberto, "Poder presidencial y crisis política en Argentina", en Saba, Roberto et al., Poder Ejecutivo, Buenos Aires, Editores del Puerto, SELA, 2007.

14 Cfr., por todos, Linz, Juan J., La quiebra de las democracias, trad. de Rocío de Terán, México, Alianza, 1990, passim; Linz, Juan J., "Los peligros del presidencialismo”, en Diamond, L. y Plattner, M., El resurgimiento global de la democracia, México, UNAM, Instituto de Investigaciones Sociales, 1997; por último, Linz, Juan J., "Democracia presidencialismo o parlamentaria ¿Qué diferencia implica?”, en Linz, Juan J. y Valenzuela, Arturo (comps.), La crisis del presidencialismo. Perspectivas comparativas, trad. de Rocío de Terán Troyano, Madrid, Alianza, 1997, t. I. 
Un ensayo retrospectivo de reconstrucción de la experiencia suscitada en los últimos años podría ser conducente para demostrar esta noción. Mencionaré algunos desarrollos de la práctica constitucional referidas al dictado de los Decretos de Necesidad y Urgencia como ejemplo. Esto, como se verá, tiene una relación sumamente estrecha respecto de las posibilidades de emplear, con sentido, el sintagma "el sistema presidencialista argentino es un sistema resiliente”. En el próximo acápite me ocupo de este tema.

\section{PRESIDENCIALISMO, RESILIENCIA Y DECRETOS DE NECESIDAD Y URGENCIA: UNA PEQUEÑA MUESTRA DE LA PRÁCTICA CONSTITUCIONAL ARGENTINA}

La Convención constituyente argentina de 1994, como ya dije, tuvo una telesis atenuadora. De la misma ley de declaración de necesidad de la reforma puede colegirse esta finalidad. ${ }^{15}$ Ahora bien, que esta intención haya sido puesta en práctica es discutible. El presidencialismo argentino, antes de la reforma, se encontraba hipertrofiado. ${ }^{16}$ Luego de ésta, sigue estándolo. Es un lugar común, entre cierto sector doctrinario, esta afirmación. Descriptivamente, pienso, están en lo correcto: el sistema presidencial continúa exacerbado.

Ahora bien, en este marco deberíamos interrogarnos por la introducción de los Decretos de Necesidad y Urgencia en un sistema institucional presidencialista. En este sentido, la dicotomía es obvia. Por un lado, una interpretación sostendría que la inclusión de esta atribución estuvo orientada a dotar de mayores competencias al Poder Ejecutivo. El fundamento de ella sería, sin duda, el siguiente: antes de la reforma, el texto constitucional no consagraba de un modo expreso la posibilidad del dictado de estas medidas.

De ahí que, por ejemplo, destaque María Angélica Gelli que estos reglamentos proponían un sinnúmero de cuestiones problemáticas con anterioridad a su inclusión en el texto constitucional. ${ }^{17}$ Específicamente, según ella,

\footnotetext{
15 Véase Ley núm. 24.309, en especial el artículo 2o., literal "A”, denominado “Atenuación del sistema presidencialista".

16 Cfr. Nino, Carlos S., Fundamentos de derecho constitucional. Análisis filosófico, jurídico y politológico de la práctica constitucional, Buenos Aires, Astrea, 2a. reimp., 2002.

17 Cfr. Gelli, María Angélica, Constitución de la Nación Argentina. Comentada y anotada, 3a. ed., Buenos Aires, La Ley, 2005, p. 834.
} 
la principal dificultad era la legitimidad de la práctica de estos decretos. Para así concluir, señala que ello se deriva de la inexistencia de atribución expresa por parte de la Constitución. ${ }^{18}$ Empero, en todos los casos trataron de determinar si el presidente estaba facultado para su dictado, ante la inexistencia de una expresa autorización de parte de la Constitución. En tanto estaba huérfana de previsión al respecto, no pocos autores consideraron que se trataba de una laguna normativa. Vale decir, el sistema constitucional no poseía respuesta normativa para este problema: cuál era el estatus deóntico de esa competencia presidencial. ${ }^{19}$ A partir de esto, las posiciones se dividían. Por un lado, existían quienes consideraban que debía ser colmada

18 Si bien acuerdo respecto al problema identificado, no lo hago con referencia al concepto empleado. Entiendo que son dos cuestiones conceptualmente distintas. En este sentido, a mi criterio, debería disociarse el problema de la legalidad de cierta acción que, básicamente, consiste en la determinación del status deóntico de una específica conducta - i. e. si ella es obligatoria, permitida o prohibida-. Un problema distinto, sin embargo, consiste en preguntarse por la legitimidad de una acción determinada. El primero de ellos es una cuestión que depende de la identificación del derecho. Vale decir, de la interpretación del sistema jurídico, a fin de obtener una respuesta acerca de si el derecho (i. e. la Constitución) determina, como dije, el estatus deóntico de cierta acción. El segundo - el problema de la legitimidad - posee un campo distinto, pues, intuyo, éste debe llevarse a cabo en el terreno de la filosofía política. Esto es, el juicio de legitimidad es uno de tipo ético político. En este ámbito, entonces, en el caso de los decretos de necesidad y urgencia, el debate trasunta por la justificación de estas medidas en una democracia constitucional en la que el rol del Congreso, como expresión de las voces y los desacuerdos que en la sociedad ocurren, posee un plus de representatividad y una mayor cualidad deliberativa y democrática. Como podrá advertirse, las críticas que al dictado de estos decretos se efectuaron a lo largo de la historia constitucional de nuestro país estaba asentada sobre ambos andariveles. De una parte, no existía norma constitucional que determinara si esa conducta estaba permitida o prohibida y, de otro costado, la inconveniencia desde un punto de vista democrático por la ausencia de deliberación y debate que son necesarios en el dictado de estas disposiciones de excepción. Señala la distinción entre esos conceptos, Ernesto Garzón Valdés. Véase, Garzón Valdés, Ernesto, "El concepto de estabilidad en los sistemas políticos", cit.; El velo de la ilusión. Apuntes sobre una vida argentina y su realidad politica, Buenos Aires, Sudamericana, 2000, pp. 288 y ss., y, por último, "Derecho y democracia en América Latina", en Carbonell, Miguel y Vázquez, Rodolfo (comps.), El Estado de derecho: dilemas para América Latina, Lima, Palestra, 2009, pp. 144-182.

19 Alchourron y Bulygin definen de modo formal una laguna normativa en el sentido de que un $\mathrm{Caso}_{1}$ de un $\mathrm{UC}_{\mathrm{j}}$ (Universo de Casos, JMM) es una laguna del sistema normativo $\alpha$ en relación a un $\mathrm{USmax}_{\mathrm{k}}$ (Universo de Soluciones Maximales, JMM) significa que $\alpha$ no correlaciona $\mathrm{C}_{1}$ con ninguna solución del $\mathrm{USmax}_{\mathrm{k}}$. Cfr. Alchourron, Carlos y Bulygin, Eugenio, Introducción a la metodología de las ciencias jurídicas y sociales, Buenos Aires, Astrea, 2006, p. 49. 
otorgándole esa competencia al presidente. Para así razonar, entendían que el principio de separación de poderes no era uno de tipo estricto y que, en suma, ante situaciones de crisis, la ortodoxia constitucional debía ceder. Ante la necesidad, la urgente necesidad, se necesitaban medidas súbitas y extremas para paliar una determinada crisis. A estas circunstancias, es obvio, añadían ciertos prejuicios en contra del Poder Legislativo. Éste era visto como un pesado lastre con el que cargar, ya que él necesita de tiempo y reflexión para funcionar, lo que era imposible en las situaciones de emergencia que este tipo de medidas venían a paliar. Por el contrario, la otra postura sostuvo, por vía de un argumento sistémico y a contrario, que si la Constitución no decía nada al respecto, debía a ese silencio otorgarle cierto valor: negar la potestad. Para ello, quizá, las razones eran justamente las contrarias a las empleadas por los apologetas de las medidas extremas. De este modo, el argumento se basó sobre tres soportes: (i) principio de separación de poderes; (ii) ámbito competencial del Poder Legislativo, y, por último, (iii) carencia de arraigo textual.

Esta fue la discusión doctrinaria previa a la reforma constitucional. Empero, una vez que ella se produjo, las diatribas no se aplacaron. La controversia continuó girando sobre cómo interpretar estas medidas de excepción y cómo ellas se relacionaban con la intención de atenuar el presidencialismo argentino. Por un lado, podría entenderse que introducir la competencia al presidente para dictar decretos de necesidad y urgencia importa una forma de vigorizar el presidencialismo argentino.

Sin embargo, este no será el camino que seguiré aquí. En efecto, a mi criterio, la introducción de estas medidas debe vincularse con la necesidad de asegurar condiciones de gobernabilidad. Esta intuición, me parece, es compartida por diversos autores que, desde diferentes puntos de vista, analizan esta cuestión. Por ejemplo, Gabriel Negretto sostiene que deben concebirse estas medidas como instrumentos de gobernabilidad necesarios para hacer frente a una situación de crisis en la que los mecanismos de pesos y contrapesos operan como un obstáculo para la adopción de cambios legislativos. Así, funcionan como sostenedores de un gobierno en contextos institucionales con escasa capacidad para producir rápidas decisiones o cambios de política legislativa en situaciones críticas. ${ }^{20}$ Por supuesto, y como reconoce este autor, los efectos de la inserción de estas medidas no

20 Cfr. Negretto, Gabriel, "El constitucionalismo puesto a prueba: decretos legislativos y emergencia económica en América Latina”, Isonomía, 14, p. 82. 
son neutrales respecto de la legitimidad de un régimen democrático. En este sentido, señala: 1) debilitan los mecanismos de rendición de cuentas; 2) afectan la legitimidad del proceso legislativo; 3) erosionan la confianza de los ciudadanos en la credibilidad y estabilidad de las decisiones de gobierno. ${ }^{21}$ En suma, de lo que se trata es del otorgamiento de atribuciones que puedan ser empleadas como un medio de hacer efectiva la gobernabilidad ante situaciones de bloqueo. ${ }^{22}$

Más allá de cuál sea la relación de estas medidas con la finalidad del aseguramiento de mejores condiciones de gobernabilidad, esto por sí solo no dice nada respecto de la atenuación (o no) del marco institucional. Entiendo que la inserción en el texto constitucional de estas medidas puede ser vista como una "hipótesis atenuadora". Es a partir del expreso cuerpo constitucional que se sigue que la finalidad primigenia de la regla plasmada en el artículo 99, inciso 3, de la CN, es la restricción. De ahí que, entonces, pienso que esta norma pretendía limitar el dictado de este tipo de normas. Las autorizaba, es cierto, pero con una clara vocación limitante. Esta interpretación cuenta con el respaldo de la Corte Suprema Argentina:

...el texto [del artículo 99, inc. 3, CN] es elocuente y las palabras escogidas en su redacción no dejan lugar a dudas de que la admisión del ejercicio de facultades legislativas por parte del Poder Ejecutivo se hace bajo condiciones de rigurosa excepcionalidad y con sujeción a exigencias formales, que constituyen una limitación y no una ampliación de la práctica seguida en el país. ${ }^{23}$

\section{De ahí que, entonces, sea posible pensarlos como propongo.}

21 Cfr. Negretto, Gabriel, "Negociando los poderes del presidente: reforma y cambio constitucional en la Argentina", Desarrollo Económico, vol. 41, núm. 163, 2001, pp. 411-443.

22 Cfr. Negretto, Gabriel, "Negociando los poderes del presidente: reforma y cambio constitucional en la Argentina”, y, del mismo autor, “¿Gobierna solo el presidente? Poderes de decreto y diseño institucional en Brasil y Argentina", Desarrollo Económico, vol. 42, núm. 167, 2002, pp. 377-404. También, Dieter Nohlen entiende que se trata de modificaciones de las atribuciones del Poder Ejecutivo destinadas a mejorar las condiciones de gobernabilidad. Cfr. Nohlen, Dieter, El institucionalismo contextualizado. La relevancia del contexto en el análisis y diseño institucionales, México, Porrúa-UNAM, 2006, passim, y, del mismo autor, "El Poder Ejecutivo en el presidencialismo. Alternativas en debate", en A. Ellis et al., (coords.), Cómo hacer que funcione el sistema presidencial, Mexico, UNAM-IDEA, 2009, pp. 37-44.

23 Cfr. CSJN, Fallos, 333:633 (“Consumidores Argentinos c/ EN - PEN - Dto. 558/02 - Ley 20.091 s/ Amparo Ley 16.986” [19/5/2010]). 
Ahora bien, para el estudio detenido de los efectos de aquella finalidad constituyente, debería efectuarse un análisis más o menos detenido respecto de cómo fue el desarrollo de la práctica del presidencialismo argentino. En especial, sería necesario detenerse en cómo la Corte Suprema respondió al dictado de estas medidas y cómo lo hizo el Congreso de la Nación al momento de la reglamentación de esta excepcional atribución. ${ }^{24}$ Sin embargo, pienso, basta con que haga referencia a que, en términos generales, la jurisprudencia fue muy poco estricta al momento de ejercer el control de constitucionalidad sobre este tema. En el mismo sentido, la ley reglamentaria ha sido, en general, criticada por la consagración de un espacio poco exigente en instancias de control. De ahí que, entonces, es dable concluir que nuestra hipótesis atenuadora no ha sido verificada en la práctica constitucional; la atenuación declamada no ha sido comprobada.

A esta altura, pienso, sería necesario interrogarse sobre lo siguiente: ¿qué es lo que hace que el presidencialismo argentino sea tan característicamente "obstinado"? Vale decir, que sea tan dificultosa la posibilidad de atenuarlo. Por supuesto, una forma de responder a este interrogante es sostener que el medio elegido por el constituyente no fue el adecuado. De tal modo, recurriría nuevamente a la introducción de la atribución presidencial para el dictado de decretos de necesidad y urgencia. Sin embargo, la respuesta aquí es obvia, y lo es por algunas de las razones que ya expuse. Las dificultades que genera la dinámica del presidencialismo son las que motivan la necesidad de introducción de ciertos parches institucionales que sirvan como desbloqueadores de las situaciones de crisis y bloqueo que son sistémicamente posibles. Es por eso que, entonces, el problema no es tanto del medio empleado - i. e., introducción de decretos de necesidad y urgencia y otras instituciones - , sino que, antes bien, se trata de las dificultades propias del contexto institucional sobre el que se actúa. Esto es, es un problema de cómo interactúan las intenciones atenuadoras con un sistema presidencial argentino hipertrofiado que genera una dinámica institucional que necesita de este tipo de medidas para evitar bloqueos constantes y posibles entre Poder Legislativo y Poder Ejecutivo. Pero, si esto es así, entonces, el punto

24 Un análisis de la ley reglamentaria puede verse en Millón Quintana, Joaquín y Mocoroa, Juan M., "El presidencialismo sin happy ending. A propósito de la ley 26122 y los decretos de necesidad y urgencia”, JA 2007-I-1328, y Mocoroa, Juan M., “Atribuciones del Poder Ejecutivo Nacional”, en Hernández, Antonio M. (h) (dir.), Derecho constitucional, Buenos Aires, La Ley, 2012, t. II, pp. 1351-1406. 
es que aun cuando se hubiera querido atenuar la competencia del titular del Poder Ejecutivo Nacional, en verdad se le otorga un remedio para obviar instancias de bloqueo. De esta manera, en verdad, no se hace otra que otorgarle mayores competencias que las que tenía previamente adjudicadas.

\section{PRESIDENCIALISMO Y RESILIENCIA INSTITUCIONAL}

Luego de lo que dije en la sección anterior, la propuesta de delimitación conceptual esbozada podría ser de alguna utilidad. Es que, me parece, las dificultades advertidas para la atenuación del presidencialismo argentino son conocidas. Las respuestas a esta situación, pienso, fluctúan desde aquellas que consideran que se trata de una dificultad propia de las circunstancias de decisión constitucional, hasta, como propongo, aquellos que piensan que es una cuestión vinculada a la propia configuración de un presidencialismo exacerbado.

La primera posición, por ejemplo, es sostenida por Negretto. ${ }^{25}$ Para este autor, el momento de decisión constitucional, especialmente respecto de cuestiones de diseño institucional, posee algunas particularidades. En este sentido, señala, deriva de un proceso de elección colectiva determinada por: (i) las preferencias, (ii) el poder de negociación y (iii) el constreñimiento de los individuos que en él participan.

Ahora bien, la dinámica de estos momentos depende, a su vez, de tres factores causales: (a) las expectativas de los actores sobre sus posiciones políticas futuras; (b) el tipo de recursos y estrategias implementadas por las partes negociadoras, y (c) las reglas de procedimiento que estructuran el proceso de creación constitucional. De ahí que, parece, los partidos políticos que son suficientemente grandes para ganar una mayoría legislativa y formar gobierno tienden a preferir un sistema parlamentario con ejecutivos relativamente fuertes e independientes, mientras que los partidos pequeños normalmente insisten en ejecutivos con menos autonomía y poderes efectivos frente a la asamblea.

Con este arsenal teórico formal, analiza los contextos de decisión constitucional en los que se intenta, o se logra, modificar las instituciones del

25 Además, de los trabajos ya citados del autor, resulta interesante consultar, Negretto, Gabriel, "Hacia una nueva visión de la separación de poderes", en Carbonell, Miguel y Vázquez, Rodolfo (comps.), El Estado de derecho: dilemas para América Latina, Lima, Palestra, 2009, pp. 183-222. 
presidencialismo, en especial en Argentina. Para él, la falta de éxito de los intentos de limitación efectiva del presidencialismo se debe, más que nada, a cómo conjugan su interacción cada uno de los jugadores relevantes en esos contextos. De este modo, me parece, puede suponerse que son dos las preferencias generalizadas a tener en cuenta al momento de interactuar en contextos de decisión constitucional. Éstas, para resumir groseramente, pueden identificarse con dos valores que, en rigor, serán los que dominarán cada uno de sus cursos de acción. Éstos son la eficacia y el control. Así, los partidos pequeños y que, en verdad, no tengan posibilidades (ni expectativas reales) de triunfar en elecciones próximas dominarán estrategias de interacción dirigidas a la instauración de instituciones que favorezcan y faciliten el control del Ejecutivo. Al contrario, quienes piensen que tienen posibilidades seguras de ganar las elecciones preferirán instituciones que garanticen la eficacia y establezcan menos instancias de control. Pero el punto, entonces, es que las posibilidades de éxito de los intentos de limitación de las instituciones destinadas a garantizar la eficacia en desmedro del control son, cuando menos, bastante remotas.

Es que, adviértase, "aquellos individuos que cuentan con suficiente apoyo electoral para esperar ganar o retener la presidencia son a menudo los mismos que tienen el poder de iniciar y/o controlar un proceso de cambio constitucional. Dicho de otra manera, aquellos que se hallan en posición para cambiar el sistema son precisamente los que menos interés tienen en hacerlo". ${ }^{26}$ Entonces, si esto es así, las posibilidades de éxito de una reforma institucional tendente a efectivizar controles respecto del presidencialismo son muy pocas. Es que "siendo que el partido que controla o espera controlar la presidencia difícilmente admitiría reducir los poderes del ejecutivo, las condiciones bajo las cuales se puede pasar de un régimen presidencial a otro de tipo parlamentario son altamente restrictivas". ${ }^{27}$

De cualquier modo, es posible sostener que también debe considerarse el poder de negociación relativo del partido que controla al Ejecutivo al momento de diseñar una Constitución, dado que, si éste tiene suficientes herramientas para, de algún modo, doblegar las intenciones primarias del partido político que, en ese momento, esté en el poder, quizá logre un mayor equilibrio entre eficacia y control. Si bien debe destacarse, no podrá

26 Cfr. Negretto, Gabriel, "Negociando los poderes del presidente: reforma y cambio constitucional en la Argentina", cit., p. 438.

27 Idem. 
ver satisfecha su pretensión del modo que, en un primer momento, hubiese querido. Es posible que, más allá de eso, puedan obtener limitaciones a las directivas de eficacia, $y$, de este modo, obtener un mayor equilibrio. Sin embargo, esto no es esperable. ${ }^{28}$

Me parece muy poderosa esta estrategia de argumentación. Sin embargo, y pese a que la considero en líneas generales correcta, pienso que es insuficiente para la explicación de los fenómenos que describí muy someramente. De tal modo, sería posible vincular esas características no tanto con la forma de interacción de los actores políticos relevantes, sino que, antes bien, con las propias características del presidencialismo. Y, en este orden de ideas, la noción de resiliencia que propuse podría explicar esta extraña "estabilidad" del presidencialismo. Además, adviértase, se trata de una explicación distinta; o bien que, al menos, se mueven en niveles disociados de análisis. La posición de Negretto se dirige a la explicación de las situaciones de fracaso, con la mirada puesta en los actores de que se trata, más que nada en los contextos de decisión constitucional. No obstante, según mi criterio, resulta necesario ampliar el análisis y que sigamos colocando la vista en el sistema institucional para, entonces, estar en condiciones de brindar una respuesta institucionalista. Aquí, de este modo, deberíamos seguir pensando en cómo interactúan los sujetos en la etapa post constituyente. Es decir, qué tipo de dinámicas son las que va a generar el propio sistema institucional. En mi opinión, es el propio presidencialismo el que posee las propiedades que generan las condiciones necesarias para que podamos identificar las reacciones a las que aludí en este trabajo. Esto es, el sistema presidencial como un sistema resiliente en sentido positivo y en sentido negativo $(\mathrm{R}-\wedge \mathrm{R}+)$.

Con la incorporación del artículo 99, inciso 3o., a la $\mathrm{CN}$, y su reglamentación por parte de la Ley núm. 26.122, intuyo, nos encontramos ante lo que he denominado "resiliencia en sentido positivo" ( $\mathrm{R}+$ ). El presidencialismo hipertrofiado tornó inocua cualquier reglamentación. Cada una de las versiones de atenuación por medio de los decretos de necesidad y urgencia otorgó mayores competencias al titular del Poder Ejecutivo Nacional. Los inputs atenuadores ensayados otorgaron mayor vigorosidad a un sistema institucional de por sí robusto. De este modo, actúan como si se tratara de

28 Cfr. Negretto, Gabriel, "Negociando los poderes del presidente: reforma y cambio constitucional en la Argentina”, cit., y Negretto, Gabriel, “¿Gobierna solo el presidente? Poderes de decreto y diseño institucional en Brasil y Argentina", cit., pp. 377-404. 
"prótesis capacitadoras". ${ }^{29}$ No limitan, ayudan. No atenúan, refuerzan. En fin, el sistema posee la característica de sobreponerse a los intentos exógenos de atenuación de modo de trastocarlo y emplearlos en provecho propio.

El ejemplo más claro de lo que denomino "resiliencia negativa" (R-) podemos encontrarlo en la figura del jefe de gabinete. La introducción de este funcionario pretendía disociar las funciones del presidente $\mathrm{y}$, de ese modo, atenuar el presidencialismo. En este sentido, la reforma constitucional de 1994 pretendió amputar un cúmulo de competencias, anteriormente en cabeza del jefe de Estado, que hacían a la administración cotidiana del país, imputándoselas, ahora, al jefe de gabinete. De esta forma, se quiso distinguir un ámbito de atribuciones, competencias y funciones referidas a: (i) las líneas políticas más amplias e importantes - i.e., "función gubernamental"-, el desarrollo de las grandes líneas de acción del gobierno, y (ii) las que se refieren a la administración cotidiana del país. La intención era que, en líneas generales, (i) fuera depositada en el titular del Poder Ejecutivo y (ii) en manos del jefe de gabinete. Empero, no sólo por el mismo diseño constitucional, sino también por la misma práctica institucional, esta figura no es sino un decorativo trasplante constitucional, que responde a los mandatos del presidente. No se trata de una válvula de escape. Ni mucho menos. No se trata de una administración bicéfala del gobierno. La trágica experiencia vivida durante el mandato del ex presidente De la Rua demuestra que la inclusión de esta figura no pudo hacer las veces de instrumento que asegurase la gobernabilidad. ${ }^{30}$ En suma, el hiperpresidencialismo argentino es resiliente en un sentido negativo y positivo. Esto es, mantiene sus características esenciales frente a todo intento de atenuación y, aun más, o transforma los intentos atenuadores dotándolo de mayores competencias, o torna vacuos y vanos esos intentos tornándolos inocuos.

\section{CONCLUSIÓN}

Traté de argumentar que, conceptualmente, el presidencialismo argentino puede ser descrito como dotado de —lo que llamé- resiliencia. En

29 Sobre esta idea, véase Millón Quintana, Joaquín y Mocoroa, Juan M., "El presidencialismo sin happy ending. A propósito de la ley 26122 y los decretos de necesidad y urgencia", cit.

30 Sobre esto, véase García Mansilla, Manuel J. y Ramírez Calvo, Ricardo, "Presidencialismo vs. Parlamentarismo. Una discusión sobre el sexo de los ángeles", Anales de la Academia Nacional de Ciencias Morales y Politicas, Buenos Aires, 2009, separata. 
su sentido positivo implica que el presidencialismo argentino posee una capacidad adaptativa, propia de la variante hiperpresidencialista, según la cual absorbe todo intento atenuador de sus competencias $(\mathrm{R}+)$. $\mathrm{Al}$ mismo tiempo, la posee en un sentido negativo, dado que debería aceptarse que otros inputs atenuadores son inocuos.

Habré logrado mi propósito si se comprende que esta propiedad fantástica del hiperpresidencialismo hace que todos los intentos de limitación sólo sean promesas vanas. La cuestión no trasunta en mentadas posibilidades de atenuación del mismo. Si vale la comparación, se asemeja a lo que en el ámbito anglófono se califican a algunas palabras como false friends. Éstas implican un grupo o pares de palabras que en dos idiomas se asemejan en su sonido o escritura, pero que poseen significados totalmente diferentes. Pues bien, los intentos de atenuación del presidencialismo funcionan, intuyo, de la misma manera. $\mathrm{O}$ bien, son pueriles debido a la mentada resiliencia negativa, o bien, son capacitadores, en tanto funciona lo que denominé resiliencia positiva.

Entonces, las posibilidades de atenuación del sistema institucional presidencialista argentino, tal y como está diseñado por la Constitución, y cómo se ha comportado en la práctica, lisa y llanamente, es imposible.

\section{BIBLIOGRAFÍA}

ACUÑA, Carlos, "Contribución”, en FERrARO, Ricardo y RAPAPPORT, Luis, Presidencialismo absoluto y otras verdades incómodas, Buenos Aires, El Ateneo, 2008.

Alchourron, Carlos y Bulygin, Eugenio, Introducción a la metodología de las ciencias jurídicas y sociales, Buenos Aires, Astrea, 2006.

ALEGRE, Marcelo, "Democracia sin presidentes", en GARGARELlA, Roberto (coord.), Teoría y crítica del derecho constitucional, Buenos Aires, Abeledo-Perrot, 2008, t. I.

ARRIMADA, Lucas, "Derecho, moral y política. Derecho constitucional, moral institucional y política democrática: sobre frenos, puentes y motores en la democracia deliberativa", en GARGARELLA, Roberto (coord.), Teoría y crítica del derecho constitucional, Buenos Aires, Abeledo-Perrot, 2008, t. I. 
BOUZAT, Roberto, "Poder presidencial y crisis política en Argentina", en SABA, Roberto et al., Poder Ejecutivo, Buenos Aires, Editores del Puerto-SELA, 2007.

ELSTER, Jon, Tuercas y tornillos. Una introducción a los conceptos básicos de las ciencias sociales, trad. de Antonio Bonanno, Barcelona, Gedisa, 1990.

García Mansilla, Manuel J. y Ramírez Calvo, Ricardo, "Presidencialismo vs. parlamentarismo. Una discusión sobre el sexo de los ángeles", Anales de la Academia Nacional de Ciencias Morales y Políticas, Buenos Aires, 2009, separata.

GARZÓN VALDÉS, Ernesto, "Derecho y democracia en América Latina", en CARBonell, Miguel y VÁzQuez, Rodolfo (comps.), El Estado de derecho: dilemas para América Latina, Lima, Palestra, 2009.

GARZÓn VALDÉs, Ernesto, El velo de la ilusión. Apuntes sobre una vida argentina y su realidad politica, Buenos Aires, Sudamericana, 2000.

GARZÓN VALDÉS, Ernesto, "El concepto de estabilidad en los sistemas políticos”, en GARZÓN VALDÉS, Ernesto, Derecho, ética y política, Madrid, Centro de Estudios Constitucionales, 1993.

Gelli, María Angélica, Constitución de la Nación Argentina. Comentada y anotada, 3a. ed., Buenos Aires, La Ley, 2005.

Hernández, Antonio M. (h), "El Poder Ejecutivo", en idem (dir.), Derecho constitucional, Buenos Aires, La Ley, 2012, t. II.

HERNÁNDEZ, Antonio M. (h), Federalismo, autonomía municipal y ciudad de Buenos Aires en la reforma constitucional de 1994, Buenos Aires, Depalma, 1997.

HernÁndez, Antonio María (h), "Presidencialismo y federalismo en la Argentina”, en SABSAY, Daniel (dir.), MANili, Pablo L. (coord.), Constitución de la Nación Argentina y normas complementarias. Análisis doctrinario y jurisprudencial, Buenos Aires, Hammurabi, 2010, t. IV.

HERNÁNDEZ, Antonio María (h), Las emergencias y el orden constitucional, 2a. ed., México, UNAM-Rubinzal-Culzoni, 2003.

LINZ, Juan J., "Democracia presidencialismo o parlamentaria ¿Qué diferencia implica?", en LinZ, Juan J. y VALENZUELA, Arturo (comps.), La crisis del presidencialismo. Perspectivas comparativas, trad. de Rocío de Terán Troyano, Madrid, Alianza, 1997, t. 1. 
LINZ, Juan J., "Los peligros del presidencialismo", en DiAmOND, L. y PlatTner, M, El resurgimiento global de la democracia, México, UNAM, Instituto de Investigaciones Sociales, 1996.

LINZ, Juan J., La quiebra de las democracias, trad. de Rocío de Terán, Alianza, México, 1990.

MAINWARING, Scott y PÉREZ LiÑÁN, Aníbal, "Democratic breakdown and survival", Journal of Democracy, volume 24, number 2, April 2013.

MiLlÓN QUiNTANA, Joaquín y MocoroA, Juan M., "El presidencialismo sin happy ending. A propósito de la ley 26122 y los decretos de necesidad y urgencia", JA 2007-I-1328.

MocoroA, Juan M., “Alberdi, las «Bases» y la construcción del Poder Ejecutivo Nacional”, Revista Mexicana de Historia del Derecho, México, segunda época, vol. XXVI, julio-diciembre de 2012.

MocoroA, Juan M., "Atribuciones del Poder Ejecutivo Nacional”, en Hernández, Antonio M. (h) (dir.), Derecho constitucional, Buenos Aires, La Ley, 2012, t. II.

NegRetTo, Gabriel, “¿Gobierna solo el presidente? Poderes de decreto y diseño institucional en Brasil y Argentina", Desarrollo Económico, vol. 42, núm. 167, 2002.

NeGRETTO, Gabriel, "El constitucionalismo puesto a prueba: decretos legislativos y emergencia económica en América Latina", Isonomía, México, núm. 14, 2001.

NeGRETTO, Gabriel, "Hacia una nueva visión de la separación de poderes", en CARBOnELl, Miguel y VÁZQueZ, Rodolfo (comps.), El Estado de derecho: dilemas para América Latina, Lima, Palestra, 2009.

NeGRETTO, Gabriel, "Negociando los poderes del presidente: reforma y cambio constitucional en la Argentina", Desarrollo Económico, vol. 41, núm. 163, 2001.

Nino, Carlos S., Fundamentos de derecho constitucional. Análisis filosófico, jurídico y politológico de la práctica constitucional, Buenos Aires, Astrea, 2a. reimp., 2002.

NoHLEN, Dieter, "El Poder Ejecutivo en el presidencialismo. Alternativas en debate", en A. ELLIS et al. (coords.), Cómo hacer que funcione el sistema presidencial, Mexico, UNAM-IDEA, 2009.

NOHLEN, Dieter, El institucionalismo contextualizado. La relevancia del contexto en el análisis y diseño institucionales, México, PorrúaUNAM, 2006. 
Oyhanarte, Julio, "Historia del Poder Judicial", en id., Recopilación de sus obras, Buenos Aires, La Ley.

RIBERI, Pablo C., "El presidencialismo exánime. Por más cooperación y mejores controles en nuestro sistema político", en varios autores, Constitución de la Nación Argentina. Con motivo del sesquicentenario de su sanción, Santa Fe, Asociación Argentina de Derecho Constitucional, 2003, t. II.

Fecha de recepción: 2 de junio de 2018.

Fecha de aceptación: 4 de febrero de 2019. 